Atıf/Citation: N. KURNAZ YETIM, E. HASANOĞLU ÖZKAN, N. SARI, "Polimerik Nanoküreler Üzerine Enzim İmmobilizasyonu ve Optimizasyonu", Süleyman Demirel Üniversitesi Fen Edebiyat Fakültesi Fen Dergisi, 14, 97-104, 2019.

\title{
Polimerik Nanoküreler Üzerine Enzim İmmobilizasyonu ve Optimizasyonu
}

\author{
Nurdan KURNAZ YETIMM ${ }^{* 1}$, Elvan HASANOĞLU ÖZKAN² ${ }^{2}$ Nurşen SARI ${ }^{2}$ \\ ${ }^{1}$ Kırklareli Üniversitesi, Fen Edebiyat Fakültesi, Kimya Bölümü, 39100, Kırklareli, Türkiye \\ ${ }^{2}$ Gazi Üniversitesi, Fen Fakültesi, Kimya Bölümü, 06500, Ankara, Türkiye \\ *yazışllan yazar e-posta: nurdankurnazyetim@klu.edu.tr
}

(Alınıs / Received: 06.11.2018, Kabul / Accepted: 28.03.2019, Yaylmlanma / Published: 31.05.2019)

\begin{abstract}
Özet: Enzimler, pek çok endüstride kullanılan, maliyetleri oldukça yüksek olan önemli materyallerdir. Katalitik tepkimelerde enzimler için şartlar uygun olsa bile yüksek sicaklık, yüksek veya düşük $\mathrm{pH}$ ve organik/inorganik çözücülerin varlığında enzimler aktifliklerini kolaylıkla kaybedebilirler. İmmobilizasyon işlemi ile birlikte, enzimlerin ekonomik açıdan kullanılabilirliğini sağlamak mümkündür. Bu amaçla, (aminometil) polistiren (APS) kaynaklı nanokürelere glukoz oksidaz (GOx) enzimi immobilize edildi ve optimizasyon parametreleri ( $\mathrm{pH}$, sıcaklık, tekrar kullanım sayısı, depolama kararlılığı, substrat derişimi) belirlendi. Serbest ve immobilize enzim için Michaelis-Menten eşitliği ile $K_{\mathrm{m}}$ ve $V_{\text {mak }}$ değerleri hesaplandı. Özellikle Pt(IV) iyonu içeren immobilize enzimin substratına karşı yüksek ilgi gösterdiği tespit edildi. 12 ay sonunda immobilize enzimlerin yaklaşı \% 85 aktifliklerini korudukları görüldü.
\end{abstract}

Anahtar kelimeler: GOx, İmmobilizasyon, Nanoküreler

\section{Enzyme Immobilization and Optimization on Polymeric Nanospheres}

\begin{abstract}
Enzymes are important materials that are used in many industries and they have a very high cost. Although the conditions for the enzymes in catalytic reactions are appropriate, enzymes can easily lose their activity in the presence of high temperature, high or low $\mathrm{pH}$ and organic / inorganic solvents. With the immobilization process, it is possible to ensure that the enzymes are economically usable. For this purpose, the glucose oxidase (GOx) enzyme was immobilized to aminomethyl polystyrene (APS) nanospheres and the optimization parameters ( $\mathrm{pH}$, temperature, reusability number, storage stability, substrate concentration) were determined. MichaelisMenten equation for free and immobilized enzyme and $K_{\mathrm{m}}$ and $V_{\max }$ values were calculated. In particular, it has been found that the substrate of the immobilized enzyme containing $\mathrm{Pt}(\mathrm{IV})$ ion shows a high affinity for the substrate. After 12 months, immobilized enzymes were found to maintain about $85 \%$ of their activity.
\end{abstract}

Keywords: GOx, Immobilization, Nanospheres

\section{Giriș}

Hücredeki kimyasal reaksiyonları katalizleyen ve protein yapısında olan enzimler, çeşitli amaçlar için hem sağlık hem de endüstri alanında kullanılmaktadırlar [1]. Kullanılan enzimlerin pahalı olması ve ürün elde edildikten sonra ekonomik olarak geri kazanılamaması maliyeti yükseltmektedir. $\mathrm{Bu}$ nedenle enzimlerin ekonomik açıdan tekrarlı kullanımını sağlamak için immobilizasyon teknikleri geliştirilmiştir. 
İmmobilizasyonun kelime anlamı, "tutuklanmış, hareketi sınırlandırılmış" demektir. İmmobilizasyon, enzimlerin ya da mikroorganizmaların fiziksel ve/veya kimyasal yöntemlerle katalitik aktifliğini koruyarak, tekrar ve sürekli kullanımını sağlamak amacıyla organik veya inorganik taşıyıcılara tutulmasıdır [2]. İmmobilizasyon işlemi, enzimin dayanıklılığını arttırdığı gibi, enzimin istenildiğinde tepkime ortamından kolayca uzaklaştırılabilmesini de sağlayacaktır. Bu nedenle enzimlerin immobilizasyonu endüstri ve sağlık alanında önemli bir yer tutmaktadır.

Enzim immobilizasyonunda çeşitli destek materyaller kullanılmaktadır. Bunlardan, polimerik nanopartiküller, immobilizasyon işleminde kullanılan yaygın destek materyallerden biridir. Nanopartiküller; doğal ya da sentetik yapıdaki polimerler ile hazırlanan, boyutları 10-1000 nm arasında değişen, hazırlama yöntemine göre nanoküre veya nanokapsül olarak adlandırılan ve etken maddenin partikül içinde çözündürüldügü, hapsedildiği ve/veya yüzeye adsorbe edildiği yada bağlandığı matriks sistemlerdir [3]. Nano veya mikro yapılı polimerik kürelerin geniş yüzey alanına sahip olmaları, ortamdan kolay uzaklaştırılabilmeleri ve daha düşük topaklanma göstermeleri nedeniyle performansların daha iyi sonuçlandığg görülmektedir [4].

Glukoz oksidaz (GOx), glukoz tayininde analitik reaktif olarak, özellikle enzim elektrot uygulamalarında yaygın olarak kullanılmaktadır. Bu elektrotlar, son yıllarda oldukça artış gösteren diyabet hastalığının en önemli tanı materyalidir Bunun yanı sıra içeceklerde ve diğer bazı gıdasal ürünlerde glukoz tayini, glukoz enzim elektrotları kullanılarak yapılmaktadır [5].

Bu çalışmada, küre yapısındaki (aminometil) polistiren (APS) ile 5-kloro-2-hidroksi benzaldehit'in katılma-ayrılma tepkimesi sonucunda APS-SchCl ligandı (Şekil 1a), daha sonra $\mathrm{Pt}(\mathrm{II}) / \mathrm{Pt}(\mathrm{IV})$ iyonlarını kullanılarak koordiasyon polimerleri (Şekil 1b) Öğütcü ve arkadaşları tarafindan yapılan sentez yöntemine göre hazırlandı [6]. Hazırlanan polimerlere, glukoz oksidaz enzimini (GOx) immobilize edilerek, enzimin optimum şartları ve kinetik parametreleri araştırıldı $[3,7]$.

\section{Materyal ve Metot}

Çalışmada kullanılan APS (1 g, 2,0 mmol/g - $\mathrm{NH}_{2}$ yüklü), 5-kloro-2-hidroksi benzaldehit, $\mathrm{PtCl}_{2}, \mathrm{PtCl}_{4}$ 4-Aminoantipirin (4-AAP), Fenol, Sodyum Dihidrojen fosfat $\left(\mathrm{NaH}_{2} \mathrm{PO}_{4}\right)$, Disodyum hidrojenfosfat $\left(\mathrm{Na}_{2} \mathrm{HPO}_{4}\right)$, Boraks $\left(\mathrm{Na}_{2} \mathrm{~B}_{4} \mathrm{O}_{7}\right)$ Sigma-Aldrich, $\beta$-Glukoz Oksidaz (Aspergillus niger'dan elde edilen) (192 U/mg) Glukoz, Peroksidaz enzimi (HRP) (yaban turbundan elde edilen) $\left(\geq 250 \mathrm{U} / \mathrm{mg}\right.$ ), Sigma, Fosforik Asit $\left(\mathrm{H}_{3} \mathrm{PO}_{4}\right)$, Sodyum Asetat $\left(\mathrm{CH}_{3} \mathrm{OONa}\right)$, Aldrich firmasından temin edildi. UV-GB spektrumları, UV-1800 ENG240V, SOFT model spektrofotometre ile 700-180 nm aralığında alındı. Modifiye edilmiş polimerlerin ${ }^{1} \mathrm{H}-\mathrm{NMR}$ spektrumları DMSO- $\mathrm{d}_{6}$ çözücüsünde, iç standart olarak TMS kullanılarak Bruker Spectrospin Avance DPX-400 cihazı ile kaydedildi. Element analizleri LECO, CHNS-932 cihazı ile yapıldı. IR spektrumları $\mathrm{KBr}$ peletlerinde Mattson-5000 FT-IR cihazı üzerinde kaydedildi. bileşiklerin taramalı elektron mikroskobu (SEM), Au-Pd ile kaplandıktan sonra, JEOL JEM 100 CX II cihazı kullanılarak yapıldı.

\subsection{APS-SchCl, APS-SchCl-M, (M:Pt(II)/Pt(IV)) nanokürelerinin sentezi}

APS-SchCl, APS-SchCl-Pt(II) ve APS-SchCl-Pt(IV) koordinasyon polimerleri Öğütcü ve arkadaşları tarafından uygulanan yönteme göre sentezlendi ve karakterize edildi [6]. 


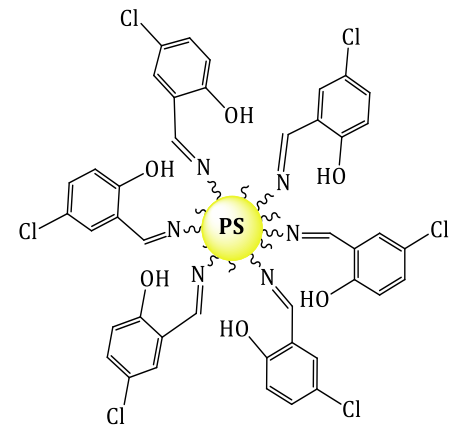

a

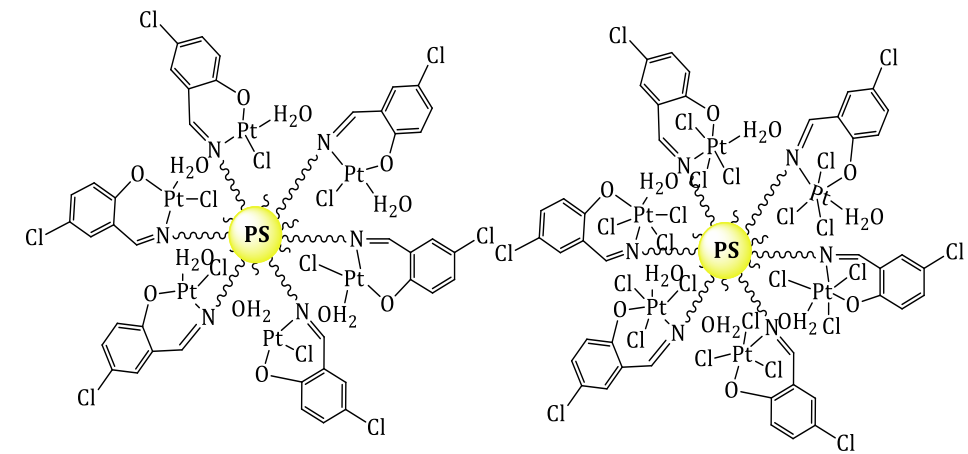

b

Şekil 1. (a) APS-SchCl, (b) APS-SchCl-Pt(II) ve APS-SchCl-Pt(IV) polimerik nanokürelerin açık yapilar1

\subsection{APS-SchCl, APS-SchCl-M, (M:Pt(II)/Pt(IV)) nanokürelerin üzerine GOx enziminin immobilizasyonu ve optimizasyonu}

GOx enziminin immobilizasyonu için, $10 \mathrm{mg} \beta$-Glukoz oksidazın $10 \mathrm{~mL}$ sudaki çözeltileri hazırlanarak, 0,5'er gram APS-SchCl, APS-SchCl-Pt(II) ve APS-SchCl-Pt(IV) polimerlerin üzerlerine ilave edildi. Karıșım oda sıcaklığında manyetik karıştırıcı üzerinde 1 gün boyunca karıştırılarak immobilizasyonun gerçekleşmesi sağlandı. Daha sonra polimerik nanoküreler süzülerek alındı, $+4{ }^{\circ} \mathrm{C}$ 'de muhafaza edildi.

GOx enziminin aktivitesi, kalorimetrik Trinder metodu ile belirlendi [7]. GOx enzimi, çözeltide çözünmüş olarak bulunan oksijen gazı ile glukozu, glukonik asite yükseltgerken oksijen gaz1 $\mathrm{H}_{2} \mathrm{O}_{2}$ 'e indirgenir. Ortama boyar madde olarak 4-Aminoantipiren, fenol ve peroksidaz enzimi (HPR) ilave edilir ve pembe renkli kinonimin bileşiği oluşturulur. Bu bileşiğin maksimum absorbans yaptığ 1 dalga boyu $507 \mathrm{~nm}$ 'dir. Enzim aktivitesi bu dalga boyundaki absorbans değişim izlenerek belirlenir.

\subsection{Immobilize GOx enziminin aktifliğine pH etkisi}

pH etkisini incelemek için, APS-SchCl-GOx, APS-SchCl-Pt(II)-GOx ve APS-SchCl$\mathrm{Pt}(\mathrm{IV})-\mathrm{GO}$ x nanokürelerinden 2'şer mg alınarak yedi tüp içerisine konuldu. Üzerlerine $0,020$ g substrat (glukoz) ve tampon çözeltilerinden ( $\mathrm{pH} 3,0-9,0)$ ilave edilip oda sıcaklığında ultrasonik su banyosunda $20 \mathrm{dk}$ çalkalamalı su banyosunda karıştırıldı. Daha sonra yukarıda belirtilen her bir tüpe AAP $(10 \mathrm{mg})$, Fenol $(20 \mathrm{mg})$ ve HRP $(0,5 \mathrm{mg})$ eklendi ve $10 \mathrm{dk}$ daha karıştırma işlemine devam edildi. UV-GB spektrofotometresi ile 507 nm'deki absorbans değişimleri izlendi. Aynı işlemler serbest enzimin optimum pH'sını belirlemek içinde yapıldı.

\section{4 İmmobilize GOx enziminin aktifliğine sıcaklı̆̆ın etkisi}

Sicaklığın etkisini incelemek için, APS-SchCl-GOx, APS-SchCl-Pt(II)-GOx ve APSSchCl-Pt(IV)-GOX nanokürelerinden 2'şer mg alınarak yedi tüp içerisine konuldu. Üzerlerine $0,020 \mathrm{~g}$ substrat ve her bir immobilize nanoküre için belirlenen optimum pH'daki tampon çözeltisinden 4'er mL ilave edilip $20{ }^{\circ} \mathrm{C}-90{ }^{0} \mathrm{C}$ sıcaklıkları arasında 1sıtılan ultrasonik su banyosunda $20 \mathrm{dk}$ karıştırıldı. Bölüm 2.3'deki işlemler uygulandı. Serbest enzim çözeltisi için de aynı işlemler tekrarlandı. 
İmmobilize enzimin aktifliğine substrat (glukoz) derişiminin etkisini incelemek için, PSSchCl-GOx, APS-SchCl-Pt(II)-GOx ve APS-SchCl-Pt(IV)-GOx nanokürelerinden 2'şer mg alınarak 15 tüp içerisine konuldu. Üzerlerine 0,05M'lık substrat çözeltisinden değişen hacimlerde $(0,5-10 \mathrm{~mL})$ tüplere ilave edilerek üzerleri optimum $\mathrm{pH}$ 'daki tampon çözeltisi ile $10 \mathrm{~mL}$ ye tamamlandı. Ultrasonik çalkalamalı su banyosunda $20 \mathrm{dk}$ karıştırıldı. Bölüm 2.3'deki işlemler uyguland. Artan substrat derişimine karşı absorbans değerleri grafiğe geçirildi. Lineaweaver-Burk grafiği çizilerek $K_{\mathrm{m}}$ ve $V_{\mathrm{mak}}$ değerleri belirlendi. Serbest enzim çözeltisi için de aynı işlemler tekrarlandı.

\subsection{Immobilize GOx enziminin tekrar kullanulabilirliği}

İmmobilize enzimin tekrar kullanılabilirliğini incelemek için, PS-SchCl-GOx, APSSchCl-Pt(II)-GOx ve APS-SchCl-Pt(IV)-GOx nanokürelerden 2'şer mg alınarak 2'şer mg alınarak üzerine optimum $\mathrm{pH}$ 'daki tampon çözeltisinden $4 \mathrm{~mL}$ ve $0,020 \mathrm{~g}$ substrat ilave edilerek $20 \mathrm{dk}$ oda sıcaklığında karıştırıldı. Bölüm 2.3'deki işlemler uygulandı. Daha sonra tüp içerisindeki çözelti kısmı dekante edilerek uzaklaştırıldı. Geride kalan katının üzerine aynı işlemler uygulandı, bu işlem $30 \mathrm{dk}$ 'lık aralarla tekrar edildi.

\section{7 İmmobilize GOx enziminin depolama kararlılı̆̆ı}

İmmobilize edilmiş APS-SchCl, APS-SchCl-M (M:Pt(II)/Pt(IV)) nanokürelerden 2'şer mg alınarak tüplere konuldu. Üzerlerine belirlenen optimum pH'daki tampon çözeltiden $4 \mathrm{~mL}$ ve $0,020 \mathrm{~g}$ glukoz katısı eklenerek $20 \mathrm{dk}$ karıştırıldı. Daha sonra Bölüm 2.3'deki işlemler uygulandı ve bu işlem her ay bir defa olmak üzere oda sıcaklığında tekrarlandı.

\section{Bulgular}

Bu çalışmada, polimerik nanokürelerin gram başına yüklenen enzim miktarı (doymuşluk oran1,d.o) APS-SchCl-GOx için \% 86,45, APS-SchCl-Pt(II)-GOx için \% 93,82 ve APS$\mathrm{SchCl-Pt(II)-GOx}$ için \%94,05 olarak bulundu [8]. Bu oran aşağıdaki formüle göre hesapland:

$$
\begin{gathered}
\mathrm{A}_{507}=\varepsilon \times \mathrm{b} \times \mathrm{C}_{10 \mathrm{~mL}, 10^{-4} \mathrm{mg} / \mathrm{mL}} \\
\mathrm{A}_{\text {d.0.507 }}=\varepsilon \times \mathrm{b} \times \mathrm{C}_{10 \mathrm{~mL}, 10^{-4} \mathrm{mg} / \mathrm{mL}-\text { immobilize GOx }}
\end{gathered}
$$

Sıcaklık ve pH, sulu çözeltide enzimatik aktiviteleri değiştirebilen önemli parametrelerdir $[9,10]$. Serbest ve immobilize GOx'in enzimatik aktivitesinin en yüksek olduğu değerler \% bağıl aktivite olarak hesaplandı. Hesaplanan bu değerler sıcaklık ve pH'ya karşı grafiğe geçirildi.

\section{1 İmmobilize GOx enziminin aktifliğine pH ve sıcaklı̆̆ın etkisi}

Optimumu pH'lar; serbest GOx enzimi için pH 5, APS-SchCl-GOx için 6, ve APS-SchCl$\mathrm{Pt}(\mathrm{IV})-\mathrm{GO}_{\mathrm{X}}$ için $\mathrm{pH} 7$ olarak bulundu. APS-SchCl-Pt(II)-GOx için ise, $\mathrm{pH} 4$ ve pH 7 olarak iki tane optimum $\mathrm{pH}$ bulundu.

Serbest ve immobilize enzime ait aktifliğe $\mathrm{pH}$ 'nın etkisi ile ilgili değişimi veren grafik Şekil 2'de optimum pH değerleri Tablo 1'de verildi. 
Tablo 1. Serbest ve immobilize GOx enzimi için optimum $\mathrm{pH}$ değerleri

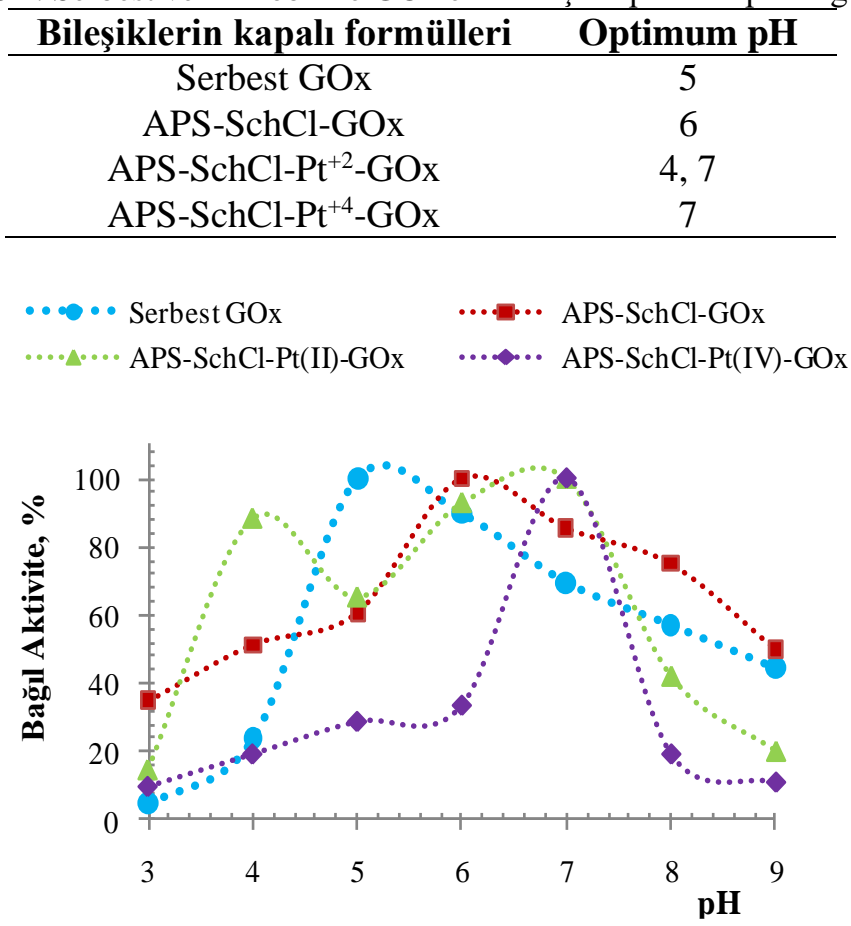

Şekil 2. İmmobilize GOx'1n aktifliği üzerine pH'nın etkisi

Serbest ve immobilize GOx için optimum sıcaklık değerleri ise, serbest GOx için optimum $30{ }^{\circ} \mathrm{C}$ ve $70^{\circ} \mathrm{C}$ olarak iki tane optimum bulunurken, immobilize APS-SchCl ligandının optimum sıcaklık değeri $50{ }^{\circ} \mathrm{C}$ olarak tespit edildi. APS-SchCl-Pt(II)-GOx' in $70{ }^{\circ} \mathrm{C}$, APS-SchBr-Pt(IV)-GOx in ise $80{ }^{\circ} \mathrm{C}$ olarak bulundu. Tablo 2 'de serbest ve immobilize enzime ait optimum sicaklık değerleri, aktifliğine sicaklığın etkisi gösteren değişim Şekil 3'de verildi.

Tablo 2. Serbest ve immobilize GOx için optimum sıcaklık değerleri

\begin{tabular}{lc}
\hline Bileşiklerin kapalı formülleri & Optimum sıcaklık $^{\circ} \mathbf{C}$ \\
\hline Serbest GOx & 30,70 \\
APS-SchCl-GOx & 50 \\
APS-SchCl-Pt(II)-GOx & 70 \\
APS-SchCl-Pt(IV)-GOx & 80 \\
\hline
\end{tabular}

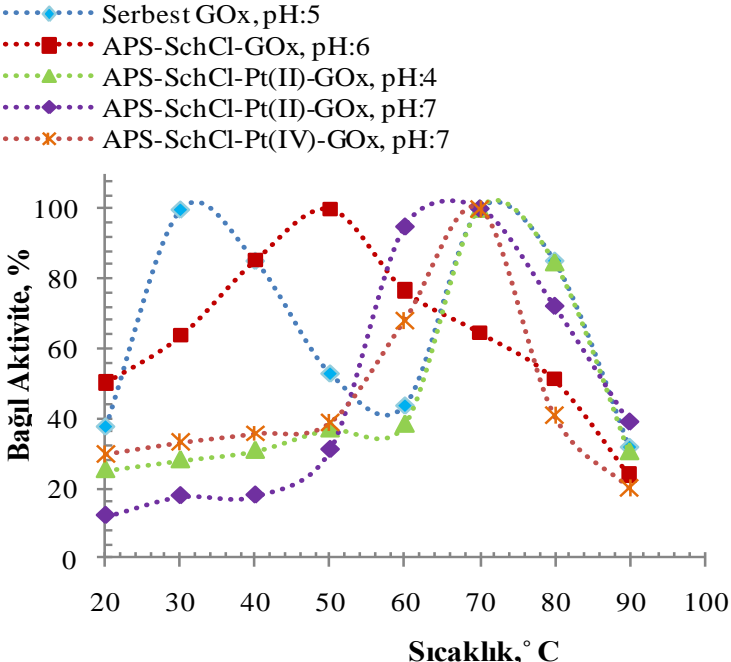

Şekil 3. İmmobilize GOx’ın aktifliği üzerine sıcaklığın etkisi 


\section{2 İmmobilize GOx enziminin aktifliğine substrat derişiminin etkisi}

Bölüm 2.5' de belirtildiği gibi, Lineaweaver-Burk grafiği, serbest ve immobilize GOx için tüm optimum koşullar da 1/S'ye karşı 1/V değerleri hesaplanarak çizildi. Bu grafiklerden $K_{\mathrm{m}}$ ve $V_{\mathrm{mak}}$ kinetik değerleri aşağıda verilen formüle göre hesaplandı [11, 12]. Bulunan değerler Tablo 3'de verildi.

$$
\frac{1}{V}=\left(\frac{K m}{V m a k}\right) \times\left(\frac{1}{S}\right)+\left(\frac{1}{V m a k}\right)
$$

- APS-SchCl-GOx, $\mathrm{pH} 6,50{ }^{\circ} \mathrm{C}$

$\triangle$ APS-SchCl-Pt(II)-GOx , $\mathrm{pH} 7,70^{\circ} \mathrm{C}$

- APS-SchCl-Pt(II)-GOx , $\mathrm{pH} 4,70^{\circ} \mathrm{C}$

- APS-SchCl-Pt(IV)-GOx, pH 7, $80^{\circ} \mathrm{C}$

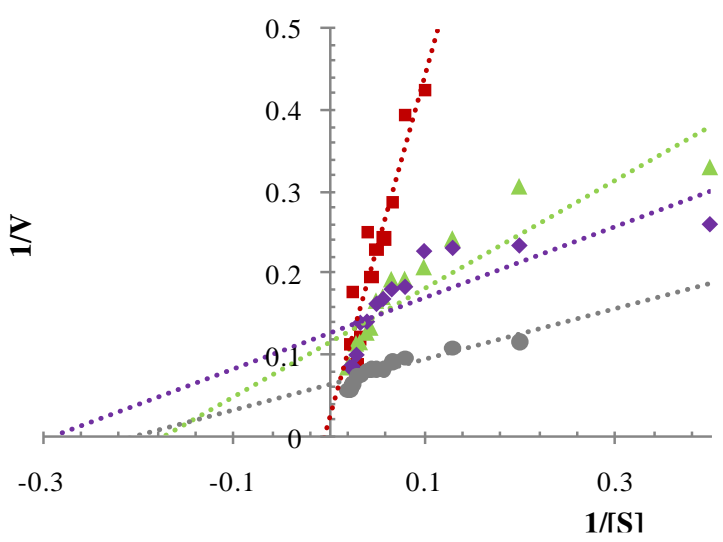

Şekil 4. GOx enzimi immobilize edilmiş polimerik nanoküreler için Lineaweaver-Burk grafiği

Tablo 3. GOx enzimi immobilize edilmiş polimerik nanoküreler için bulunan optimum şartlar ve kinetik

\begin{tabular}{cccc} 
& \multicolumn{2}{c}{ parametreler } \\
\hline \multirow{2}{*}{ Bileşiklerin kapalı formülleri } & $\begin{array}{c}\mathbf{p H}, \\
\text { Sicaklık }^{\circ} \mathbf{C}\end{array}$ & $\begin{array}{c}\text { Polimerik küreler-GOx } \\
\boldsymbol{K}_{\mathbf{m}} / \boldsymbol{V}_{\mathbf{m a k}}\end{array}$ & $\begin{array}{c}\text { Serbest GOx } \\
\boldsymbol{K}_{\mathbf{m}} / \boldsymbol{V}_{\mathbf{m}}\end{array}$ \\
\hline APS-SchCl-GOx & 6,50 & $6,13 / 49,01$ & $6,25 / 2,85$ \\
APS-SchCl-Pt(II)-GOx & 4,70 & $5,74 / 8,64$ & $5,60 / 38,29$ \\
APS-SchCl-Pt(II)-GOx & 7,70 & $3,42 / 7,86$ & $4,75 / 4,00$ \\
APS-SchCl-Pt(IV)-GOx & 7,80 & $5 / 15,92$ & $8,21 / 19,34$ \\
\hline
\end{tabular}

\section{3 İmmobilize GOx enziminin depo kararlılı̆ğ ve tekrar kullanılabilirliği}

Depolama kararlılığı enzimin saklama koşullarına bağlı bir parametredir. Serbest haldeki enzimler depolama sirasında aktivitelerini kaybederler. Bu nedenle enzim bir destek materyale bağlanırsa kararlılığının artırılması mümkün olabilir [13-16]. Bu çalışmada, serbest ve immobilize edilmiş enzimler, 12 ay boyunca $+4{ }^{\circ} \mathrm{C}$ 'de koyu renkli bir şişede saklandı. İlk aydan sonra, serbest enzimin aktivitesinde hızlı bir düşüş gözlenirken (\% 90,15) immobilize enzimin aktifliğinin $(\%$ 96,45) korunduğu gözlendi. 12 ay sonra, serbest GOx, APS-SchCl-GOx, APS-SchCl-Pt(II)-GOx, APS-SchCl-Pt(IV)-GOx'lerin aktiflikleri sirasiyla \%70.15, \%87.30, \%87.29 ve \%89.85 olarak bulundu.

İmmobilize enzimler için tekrar kullanılabilirlik grafiği incelendiğinde, 5 tekrar sonucunda immobilize GOx'in aktifliklerini \%89,00 oranında korudukları görüldü.

15 tekrar sonucunda immobilize APS-SchCl polimeri aktifliğinin \% 66,85'ini korurken $\mathrm{Pt}(\mathrm{II})$ ve $\mathrm{Pt}(\mathrm{IV})$ iyonu içeren immobilize polimerler genel olarak aktifliklerini yaklaşık \%70'ini koruduğu gözlemlendi. 


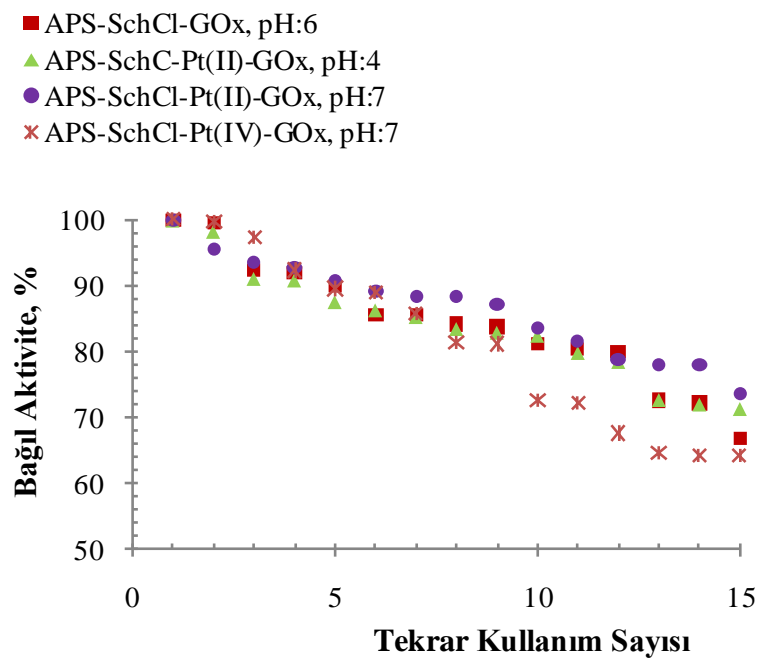

Şekil 5. GOx enzimi immobilize edilmiş polimerik nanoküreler için tekrar kullanılabilirlik grafiği

\section{Sonuç ve Yorum}

Endüstriyel uygulamalarda kullanılan enzimlerin aktivitelerini kaybetmesi sonucu maddi kayıplar meydana gelmektedir. Maliyeti en aza indirmek için enzimlerin kararlılıklarının sürdürülebilirliğii, tekrar kullanılabilirliği ve depolama kararlılığı (raf ömrü) gibi parametrelerin iyileştirilmesi önemlidir [17]. Bu çalışmada GOx enzimini polimerik desteklere immobilize ederek kararlılı̆g sağland1. Serbest GOx pH:5'de $30{ }^{\circ} \mathrm{C}$ ve 70 ${ }^{\circ} \mathrm{C}$ 'de maksimum aktiflik gösterirken, immobilize GOx'in daha farklı $\mathrm{pH}$ ve sicaklık aralığında aktif olduğu görüldü [18]. Kaynaklara göre, kataliz olayı asidik ortamda meydana geliyorsa enzimin Glu412'i, nötral ortamda oluyorsa enzimin His516'1, bazik ortamda enzimin His559'si olarak kodlanan aminoasitler etkili olmaktadır [9,10]. Bu bilgiler dikkate alındığında APS-SchCl-Pt(II)'ye immobilize edilen enzimin $\mathrm{pH} 4,0$ 'de ve APS-SchCl'e immobilize edilen enzimin ise $\mathrm{pH}$ 6,0'da aktif olmasının, enzimin Glu412 kodlu kısmının aktif rol oynamasından, kaynaklanabileceği düşünüldü. APSSchCl-Pt(IV)'e immobilize edilen enzimin pH 7,0'de aktif olmasının nedeni ise enzimin His516 kodlu kısmının rol oynamasından kaynaklanabilir. İmmobilize enzimin 5. tekrar sonunda aktifliğini \% 90 oranında koruduğu görüldü. $\mathrm{Bu}$ sonuçlardan dolayı immobilizasyonun işleminin kovalent metot ile gerçekleştiği öngörüldü.

İmmobilizasyonun yapıldığ 1 , destek üzerindeki foksiyonel gruplar, enzim moleküllerinin bağlanmasını etkileyen önemli faktörlerden biridir. Pt(II)/Pt(IV) iyonlarının (APS-SchCl) polimerik nanokürelerine bağlanmasıyla oluşan yüzeye immobilize edilen enzimin kinetik parametrelerini daha iyi olduğu görüldü. Özellikle Pt(IV) iyonu içeren immobilize desteğin, $K_{\mathrm{m}}$ değerinin serbest enzime kıyasla küçük olması immobilize enzimin konformasyon kararlılığının daha iyi olduğunu yorumu yapıldı [19]. Bütün bu sonuçlar, saflaştırma maliyeti yüksek olan enzimlerin, fonksiyonlu dendrimerler üzerine immobilize edilmesi endüstriye ekonomik katkılar sağlayabileceği yorumu yapıldı.

\section{Teşekkür}

Bu çalışma Gazi Üniversitesi Bilimsel Araştırma Projesi tarafından desteklendi. (Proje numaras1: 05/2014-02 ve 05/2016-10).

\section{Kaynakça}

[1] N. Kurnaz Yetim, "Ferrosen içeren yeni Pt(II), Pt(IV) dendrimerlerinin sentezi ve immobilizasyonda kullanımı,” Doktora Tezi, Fen Bil. Enst., Gazi Üni., Ankara, Türkiye, 2016. 
[2] A. Wiseman, "Handbook of Enzymes Biotechnology (Book style with paper title and editor)," in The application of enzymes in industry, 2nd ed., E. Horwood, Ed. Chichester, UK, 1987, pp. 274-373.

[3] E. Hasanoğlu Özkan, N. Kurnaz Yetim, D. Nartop, N. Sarı, "Influence of load on the recycling stability of nanospheres attached platinium ion for determination of glucose," J. Ind. Eng. Chem., 25, 180-185, 2015.

[4] S. Dönmez, F. Arslan, N. Sarı, E. Hasanoğlu Özkan, H. Arslan, "Glucose biosensor based on immobilization of glucose oxidase on a carbon paste electrode modified with microspheres attached L-glycine," Biotechnol. Appl. Biochem., 64 (5), 745-753, 2017.

[5] X. Wang, Y. Zhang, C. E. Banks, Q. Chen and X. Ji, "Non-enzymatic amperometric glucose biosensor based on nickel hexacyanoferrate nanoparticle film modified electrodes," Colloids Surf. B, 78, 363366, 2010.

[6] H. Öğütcü, N. Kurnaz Yetim, E. Hasanoğlu Özkan, O. Eren, G. Kaya, N. Sarı, and A. Dişli, "Nanospheres Caped Pt(II) and Pt (IV): Synthesis and Evaluation as Antimicrobial and Antifungal Agent," Pol. J. Chem., 19, 74-80, 2017.

[7] P. Trinder, "Determination of glucose in blood using glucose oxidase with an alternative oxygen acceptor," Ann. Clin. Biochem., 6, 24-27, 1969.

[8] V. Leskovac, S. Trivić, G. Wohlfahrt, J. Kandrac, D. Pericin, "Glucose oxidase from Aspergillus niger: the mechanism of action with molecular oxygen, quinones, and one-electron acceptors," Int. J. Biochem. Cell Biol., 37 ( 4), 731-750, 2005.

[9] N. Kurnaz Yetim, E. Hasanoğlu Özkan, B. Danış, H. Tümtürk, N. Sarı, "Research on the Repeated Use of Novel Ferrocene-Tagged Nanomaterial for Determination of Glucose," Int. J. Polym. Mater. Polym. Biomater., 64, 888-893, 2015.

[10] N. Kurnaz Yetim, E. Hasanoğlu Özkan, N. Sar1, "Immobilization of GOx on Trp / Trp-Fc Functionalized Nanospheres: Improved of Reusability and Stability," Gazi Univ. J. Sci., 30 (4), 114$122,2017$.

[11] A. H. Memon, R. Ding, Q. Yuan, H. Liang, Y. Wei, "Coordination of GMP ligand with Cu to enhance the multiple enzymesstability and substrate specificity by co-immobilization process," Biochem. Eng. J., 136, 102-108, 2018.

[12] P. Zhou, F. Li, W. Dong, K. Huang, Y. Chen, C. Wei, B. Ling, M. Li, “Covalent Immobilization of Glucose Oxidase onto Electrosynthesized Nanocomposite with PEDOT Derivative for Amperometric Glucose Biosensing,” Int. J. Electrochem. Sci.,13, 5294-5310, 2018.

[13] H. Azak, H. B. Yildiz, B. Bezgin Carbas, "Synthesis and characterization of a new poly(dithieno (3,2b:20, 30-d) pyrrole) derivative conjugated polymer: Its electrochromic and biosensing applications," Polym., 134, 44-52, 2018.

[14] C. Hou, D. Zhao, Y. Wang, S. Zhang, S. Li, "Preparation of magnetic $\mathrm{Fe}_{3} \mathrm{O}_{4} / \mathrm{PPy} @ \mathrm{ZIF}-8$ nanocomposite for glucose oxidase immobilization and used as glucose electrochemical biosensor," $J$. Electroanal. Chem., 822, 50-56, 2018.

[15] S. Dönmez, F. Arslan, N. Sar1, N. Kurnaz Yetim, H. Arslan, "Preparation of carbon paste electrodes including poly(styrene) attached glycine-Pt(IV) for amperometric detection of glucose," Biosens. Bioelectron., 54, 146-150, 2014.

[16] J. Shim, G. Y. Kim, S. H. Moon, "Covalent co-immobilization of glucose oxidase and ferrocenedicarboxylic acid for an enzymatic biofuel cell,” J. Electroanal. Chem., 653, 14-20, 2011.

[17] R. Ahmad, M. Sardar, "Enzyme Immobilization: An Overview on nanoparticles as immobilization matrix," Biochem Anal. Biochem., 4, 1-8, 2015.

[18] E. Çınar, S. Ercan, N. Güleşçi, "Lewatit Partikülüne Üreaz Enziminin İmmobilizasyonu," Batman Univ. J. Life Sci., 7, 124-136, 2017.

[19] N. Özdem, E. Hasanoğlu Özkan, N. Sarı, F. Arslan, H. Tümtürk, "Investigation of glucose oxidase enzyme as biocatalysts, new nanospheres attached azomethine," Macromol. Res., 22 (12), 1282-1287, 2017. 